educação de Paulo Freire e na compreensão de POLAK sobre o cuidado; socializar conhecimentos concernentes à prevenção de danos e limitações ao indivíduo cardiopata ; discutir e delinear estratégias de cuidado que permitam a esse indivíduo viver com a condição de cardiopata de forma digna. Os pressupostos que nortearam este estudo foram: o individuo cardiopata necessita dos cuidados de enfermagem na sua fase de hospitalização, anteriormente e posteriormente a ela; a prática educativa ajuda a entender melhor o processo saúde-doença e a melhor cuidar de si e da sua saúde; a convivência em grupos constituídos por individuos com a mesma condição de saúde, acrescida da troca de experiências, desenvolve potencialidades que ajudam no enfrentamento da cronicidade. Para tanto, foram delineadas estratégias de ação desenvolvidas em diferentes cenários e que culminaram com a formação de um grupo em uma Unidade Básica de Saúde. os resultados desta trajetória permitiram mostrar que o grupo é uma importante estratégia para o trabalho da enfermagem, porém constituise em um desafio que depende de algumas variáveis como: a política de saúde, a verticalização das ações de saúde, a cultura de cuidado vigente e, a assimilação, por parte dos clientes, dos valores vigentes referentes ao cuidado. Os temas emergentes do grupo e que caracterizam a condição de ser cardiopata foram caracterizados em: a temporalidade da doença, a descoberta do outro e organizando-se para viver melhor.

\title{
GRUPO OPERATIVO COMO ESTRATÉGIA PARA A ASSISTÊNCIA DE ENFERMAGEM: MULHERES EM DEPRESSÃO
}

\author{
OPERATIONAL TEAM AS A STRATEGY FOR GIVING NURSING ASSISTANCE TO WOMEN \\ SUFFERING FROM DEPRESSION
}

\section{GRUPO OPERATIVO COMO ESTRATEGIA PARA LA ASISTENCIA DE ENFERMERÍA: MUJERES CONDEPRESIÓN}

Autora: Débora Vitória Alexandrina Lisboa Villela Orientadora: Sonia Barros

\begin{abstract}
RESUMO: A partir de nossa observação durante as experiências de ensino, e no entendimento de que mulheres deprimidas expressam conflitos decorrentes de vivência depressiva e de seu cotidiano e por isso necessitam de atenção optamos por eleger estas mulheres como objeto neste estudo. Este teve como finalidade oferecer um espaço para a expressão vivencial de mulheres em depressão. Espaço operacionalizado por meio da técnica de grupo operativo, no qual os elementos do estudo, centrados na tarefa, trocaram experiências e avaliaram sua participação nos grupos. Para compreender o vivencial dessas mulheres optou-se pela pesquisa qualitativa, utilizando-se como método a pesquisa ação, em que o pesquisador e o sujeito interagem durante a pesquisa. A problemática do estudo envolveu a hipótese de que se as mulheres com diagnósticos de depressão tivessem um espaço para discutir seus problemas e expressar seus sentimentos, não haveria uma melhora em seu quadro. Os sentimentos foram reportados por seis mulheres depressivas que participaram de oito reuniões do grupo operativo. Os grupos tiveram temas disparadores elaborados com base nos relatos dos sujeitos em reunião discussão grupal: 1 - "concepção do processo saúde-doença mental"; 2 - "rede familiar e social"; 3 - "Repercussões físicas e psíquicas da doença"; 4 - "atividades de vida diária"; 5 - "Agravantes da doença"; 6 - "Resistência ao tratamento"; 7 - "Percepção de melhora"; 8 - "Necessidade de Escuta". Para a análise da discussão grupal empregou-se a análise temática das falas dos sujeitos. Os grupos operativos foram analisados nas formas de crônicas que se constituíram na sintese das reuniões grupais. Ao final, as mulheres analisaram a qualidade da ação interventiva, o grupo operativo nas suas vidas e mostraram que elas encontraram um lugar onde poderiam verbalizar sentimentos sem serem repreendidas, fortaleceram-se com o mesmo indicando sua utilização para outras mulheres com problemas semelhantes.
\end{abstract}

\section{PROCESSO DE CUIDAR EM GRUPO À LUZ DE UM REFERENCIAL CULTURAL: A EXPERIÊNCIA DE UMA ENFERMEIRA COM MULHERES QUE TIVERAM CÂNCER DE MAMA}

\author{
THE PROCESS OF TEAM CARING BASED ON A CULTURAL REFERENT: THE EXPERIENCE OF \\ A NURSE WITH BREAST CANCER PATIENTS
}




\title{
PROCESO DE CUIDAR EN GRUPO DESDE UN REFERENCIAL CULTURAL: LA EXPERIENCIA DE UNA ENFERMERA CON MUJERES CON CÁNCER DE MAMAS
}

Autora: Ana Maria Cisotto Weihermann Orientadora: Ingrid Elsen

RESUMO: Este estudo descreve uma prática assistencial de uma enfermeira, cuja finalidade foi a de prestar cuidados a mulheres que tiveram câncer de mama. O marco conceitual contempla os conceitos ambiente, cultura, ser humano/grupo, cuidado, saúde/doença e enfermagem, baseado na Teoria da Diversidade e Universidade Cultural do Cuidado de Madeleine Leininger. A prática desenvolveu-se de 13/09/99 a 06/12/99, num total de 10 encontros, na sede da Rede Feminina de Combate ao Câncer de Concórdia. As integrantes do grupo foram 6 mulheres que fazem parte do GRUPO TOQUE DE CARINHO desta instituição. O cuidado de enfermagem foi propiciado através da metodologia da OBSERVAÇÃOPARTICIPAÇÃO-REFLEXÃO, conforme preconizada por Leininger, que compreende a fase de observação e escutar ativo, uma fase de observação com participação limitada, a fase de participação com observação continuada e finalmente a fase de reconfirmação dos dados com os informantes. Ao refletir sobre a experiência, percebo a viabilidade do referencial utilizado, porque através do ouvir, interesse em compartilhar, conhecer hábitos, valores e crenças das mulheres, ocorreu a interação da enfermeira com o grupo, possibilitando o aprendizado do cuidar sob um novo aspecto, onde não se valoriza somente o biológico mas o ser humano em sua totalidade, inserido em um contexto.

\section{VISUALIZANDO POSSIBILIDADES DE RECUPERAÇÃO DO USUÁRIO DE DROGAS EM GRUPOS FOCAIS}

\author{
THE POSSIBILITY OF RECUPERATION OF DRUG USERS THROUGH FOCUS GROUPS \\ VIENDO POSIBILIDADES DE RECUPERACIÓN DEL USUARIO DE DROGAS EN GRUPOS \\ FOCALES
}

Autor: Rubens Gomes Corrêa

Orientadora: Maguida Costa Stefanelli

\begin{abstract}
RESUMO: Senti-me motivado a fazer este estudo pelo que tenho constatado na mídia e na literatura científica ou seja um número crescente de farmacodependentes, atingindo cada vez mais a população jovem. O objetivo deste estudo foi criar um espaço para que os usuários de drogas pudessem compartilhar suas experiências em busca de novos caminhos para sua recuperação. Utilizamos a pesquisa qualitativa como método, o Grupo Focal como estratégia de coleta de dados, um jogo educativo e diário de campo. A análise qualitativa dos dados permitiu a elaboração das seguintes categorias: tornando-se usuário, sofrendo por ser farmacodependente, sentindo-se isolado, tendo dificuldades para expressar-se em grupo, avaliando a conseqüência da droga, assumindo a responsabilidade, comentando a internação, discutindo sobre a recuperação, descrevendo suas crenças e valores, assumindo que é usuário de drogas e avaliando a estratégia utilizada. Através da análise mais profunda destas categorias com nova imersão dos dados, validação com pares, usuários e coordenadores da Casa de Recuperação chegamos a categoria central: Visualizando possibilidades de recuperação da farmacodependência, que inclui a subcategoria redescobrindo a família. Os resultados desta pesquisa evidenciaram a possibilidade de trabalhos que visem a recuperação do usuário de drogas que integrem a teoria, prática e ensino de enfermagem podendo se tornar realidade quando planejada adequadamente, apresentamos no final contribuições deste estudo para o ensino, pesquisa e assistência de enfermagem e em especial a educação em saúde.
\end{abstract}

